\section{Einladung zur DGNR-Jahrestagung 2016 | Jahrestagung der Österreichischen Gesellschaft für Neuroradiologie}
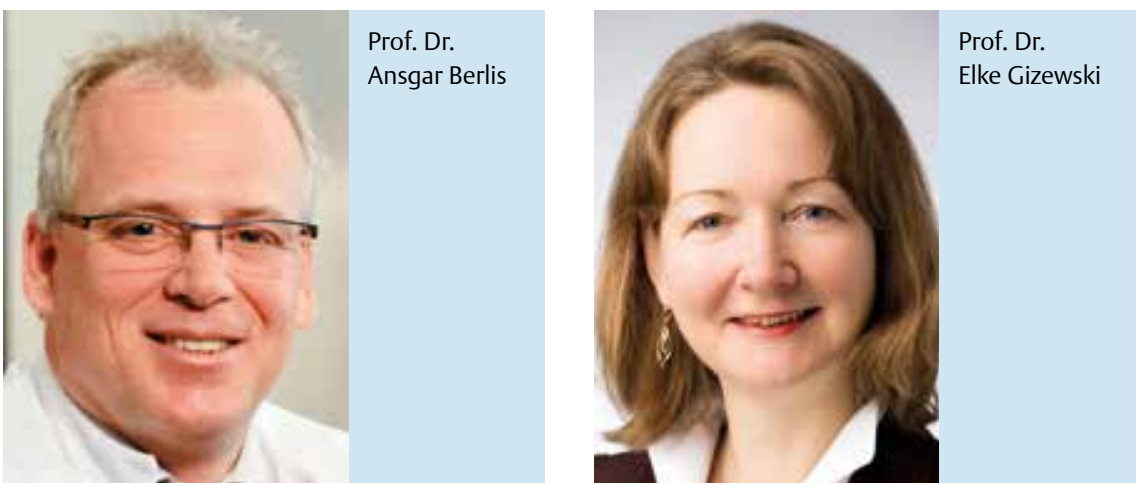

\section{neuroRAD.}

Call for Abstract
DGNR-Jahrestagung Neurorad 2016
Deadline: 28. Mai 2016
Eine Tagung lebt von der Beteiligung der
Wissenschaftlerinnen und Wissen-
schaftler, die ihre Forschungsansätze
und -ergebnisse präsentieren. Berei-
chern Sie die 51. Jahrestagung der Deut-
schen Gesellschaft für Neuroradiologie
und stellen Sie Ihre aktuellen For-
schungsergebnisse in Form von Vorträ-
gen und Postern einem fachkundigen
Publikum vor. Sie können Beiträge zu
den genannten Themen einreichen. De-
tails zur Einreichung finden Sie unter
www.neurorad.de.

Liebe Kolleginnen und Kollegen,

hiermit laden wir Sie herzlich zur 51. Jahrestagung der Deutschen Gesellschaft für Neuroradiologie ein, die wir zugleich als die 24. Jahrestagung der Österreichischen Gesellschaft für Neuroradiologie begehen. An dieser Stelle möchten wir Sie auch auf unsere erste Neuerung aufmerksam machen - der Kongress beginnt nun ganz offiziell ein Tag früher - am Mittwoch, 5. Oktober 2016 - mit spannenden und informativen Hands-on-Workshops.

Ab Donnerstag, 6. Oktober 2016, bieten wir Ihnen dann wieder das gewohnte Kongressprogramm mit wissenschaftlichen Sitzungen, Workshops, E-Poster-Sitzungen, freien Beiträgen und Industriesitzungen. Folgende Schwerpunktthemen haben wir in diesem Jahr für Sie gewählt:

- Degenerative Neuro-Erkrankungen

- Epilepsie

- Onkologie

- Interventionelle Neuroradiologie

- Schlaganfalltherapie

Nur durch die tatkräftige Unterstützung unserer MTRA können wir die gemeinsamen Aufgaben erfüllen. Daher werden wir - wie in den Vorjahren - parallel einen sehr attraktiven Fortbildungskongress für interessierte MTRA anbieten.

Kommen Sie vom 5. bis zum 8. Oktober 2016 nach Köln! Es wird sich lohnen!

Ihr Kongresspräsidium

Prof. Dr. Ansgar Berlis (Augsburg) und Prof. Dr. Elke Gizewski (Innsbruck)
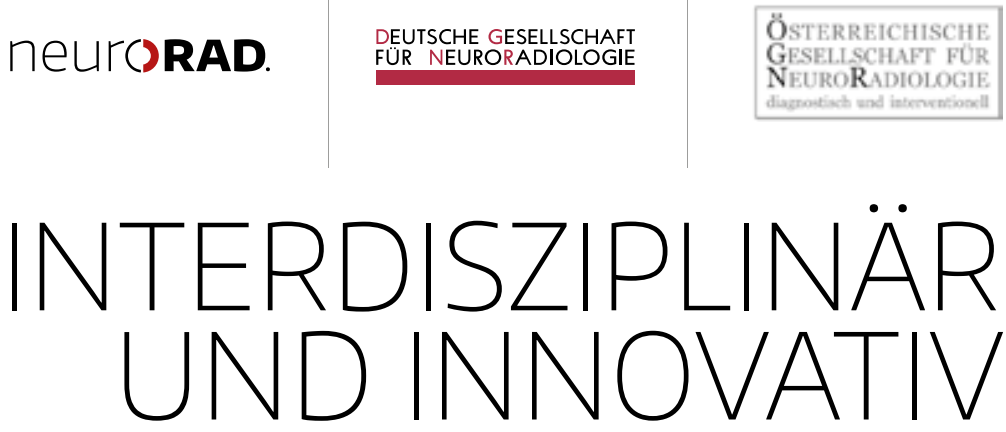

51. Jahrestagung der Deutschen Gesellschaft für Neuroradiologie e.V. In Kooperation mit der ÖGNR -

24. Jahrestagung der Österreichischen Gesellschaft für Neuroradiologie 5.-8. Oktober 2016 / Gürzenich, Köln

Kongresspräsidium

Prof. Dr. Ansgar Berlis (Augsburg) Prof. Dr. Elke Gizewski (Innsbruck)

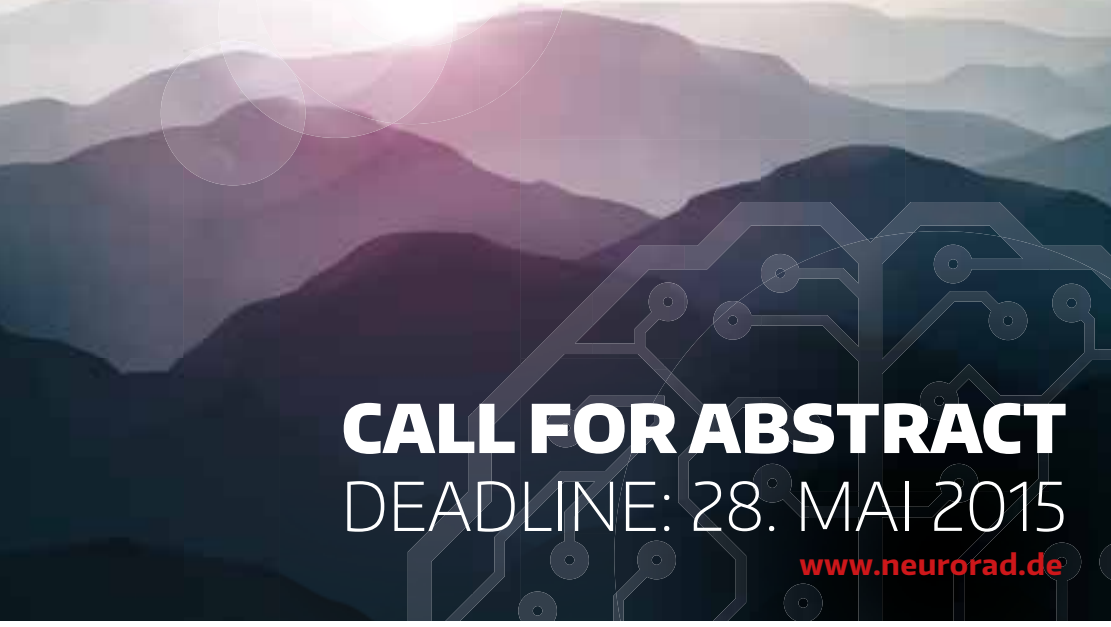

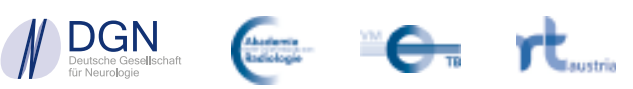

